\title{
MIRADAS COMPARTIDAS: VALENTE Y FALCES
}

\section{Concepción TORRES BEGINES}

Universidad de Sevilla

conchatb@gmail.com

$\mathbf{J}$ osé Ángel Valente y Manuel Falces se unieron para realizar varios proyectos comunes en los que buscaron relacionar imagen y literatura, interacción que interesaba a ambos de manera particular. El primero de ellos: Cabo de Gata. La memoria y la luz fue publicado por Unicaja en 1992 como resultado de una exposición que se llevó a cabo ese mismo año. En él, Valente y Falces unieron fuerzas para mostrar la interacción entre las artes, la cual parte desde su creación con el mano a mano de ambos artistas, quienes recorrieron juntos los escenarios que sirvieron de base para la elaboración de la obra en ambas disciplinas.

Manuel Falces describía así la manera de trabajar de José Ángel Valente sobre el escenario real, considerando la imagen no como algo complementario, sino como algo esencial para la creación del producto final, adquieriendo ambas disciplinas (fotografía y poesía) la misma entidad e importancia (Falces, 2000):

\footnotetext{
No le gustaba escribir en diferido sobre una imagen; es decir, con las fotos que sobre la mesa le dejaba el fotógrafo. No; él quería participar del acto fotográfico, compartir la mirada, estar en directo en el escenario, analizarlo minuciosamente. Recuerdo los paseos entre las ruinas del Higo Seco (Níjar, Almería), mientras disparaba la cámara tomaba notas constantemente en un bloc; parecía como ausente (casi ido, como los místicos).
}

La fascinación de Valente por la imagen fotográfica fue una constante a lo largo de su vida, elemento que vemos reflejado en su obra de manera muy particular, equiparando sus posibilidades interpretativas a las que la lectura podía facilitar. La técnica fotográfica es entendida como una forma de narración, a partir de la captación de un momento concreto o de una secuencia, lo que permite integrarla dentro del campo de la interpretación, dando lugar a multitud de lecturas sobre un mismo motivo (Falces, 2000): 
Siempre vio en la fotografía algo mágico: decía que una instantánea era una suerte de verbo capaz de articular infinitos relatos. A veces comentaba, con la sana ingenuidad de un niño, su admiración por el hecho de cómo con la cámara se podía congelar la vida. También, como una foto, era susceptible de infinitas lecturas, tantas como la diversidad y pluralidad de ojos que la miran (igual que ocurre en lo literario con su palabra poética).

El propio poeta hizo notar su fascinación ante el uso de la fotografía como técnica y como arte de la observación y de la descripción (Valente, 2003: 27):

Me gusta, creo, seguir esta mirada, entrar con ella en los recovecos adonde va. ¿Qué puede haber en definitiva -me pregunto- detrás de un objetivo fotográfico, sino una teoría de la paciencia, de la penetración y de la duración del mirar? Quizá todo lo demás sea secundario.

Esta misma fascinación la encontramos desde la perspectiva contraria, la del fotógrafo Manuel Falces, quien iguala la capacidad creativa de uno y otro arte y que señala la potencialización de ambas al trabajar conjuntamente, lo que posibilitó rápidamente esta compenetración de miradas que se fundieron en una sola, en un «compartir la mirada». La fotografía deja de ser algo estático, una captación de un momento concreto, para mostrar una historia que se encuentra oculta tras una imagen que toma la entidad de la palabra, se traduce en palabra y da lugar a una narración (Falces, 1998: 10):

Allí se agolparon viejas imágenes, y las palabras resucitaban espontáneamente cada vez que se las miraba y se las leía. La fotografía y la palabra rompieron el encantamiento de la vocación documental de la instantánea.

Se adentraban ambas en el reino de los bosques poéticos y destrozaron todos los cristales que creyeron que una foto era un certificado de la memoria por los siglos de los siglos.

La interacción entre palabra y fotografía funciona aquí como una ampliación de ambas perspectivas: la imagen nos lleva al lugar mismo de la creación del poema, al espacio que inspiró la conciencia poética y la reflexión, al tiempo que la palabra nos conduce a una nueva interpretación de la fotografía enfocada desde la mirada del poeta. Así, ambas manifestaciones pueden ser percibidas de manera individual, dando a su vez lugar a nuevas lecturas, al tiempo que la interacción entre disciplinas nos lleva a una apertura de horizontes, a la posibilidad de multitud de interpretaciones, lo que nos muestra el valor irremplazable de esta obra conjunta realizada alrededor de un diálogo entre las artes. En palabras de Falces, la función de la fotografía se aleja de la simple plasmación de la realidad que queda sustituida por una búsqueda de algo que se encuentra más allá, en un espacio más profundo, bajo un nuevo sentido y una nueva interpretación que lo acerca en gran medida a la poesía (Falces, 2001): «la cámara como un instrumento cuya función esencial no consiste en el registro de lo empírico, sino el resultado de la puesta en escena con su representación como único propósito». 


\section{Cabo de Gata: la memoria y la luz}

Tres son los motivos que podríamos señalar como detonantes para la creación de esta obra conjunta: la reivindicación del espacio inexplorado de Cabo de Gata como espacio natural protegido, el reconocimiento de dicho espacio como lugar de encuentro del hombre consigo mismo y con la creación y el reflejo de los dos elementos que dan título: la luz y la memoria, a través de la palabra y la imagen indisolublemente unidas.

En muchas de las referencias acerca del proyecto común sobre el que se inició la obra y el método de trabajo que se siguió durante su realización, ambos autores se muestran conscientes de que el paisaje que se presentaba ante ellos pronto dejaría de ser ese remanso de paz anclado en el pasado del que se nos habla en la introducción para dar paso con el tiempo a la entrada del progreso y la construcción. El objetivo de la publicación es eminentemente de carácter social, de compromiso con un paisaje que poco a poco estaba siendo destruido y que ambos reivindican como espacio de creación (Falces, 1998: 10, y Valente/Falces, 1992: 4):

De aquello lo único que ha quedado con el paso del tiempo, han sido las de otros bárbaros que, desde la administración, se las cargaron explanando y plantando sobre ellas una serie de árboles absurdos. Laberintos que ya -al día de la fecha- han desaparecido. [...] Es lo único que queda de él. Con ella arrancaron el testimonio de un pasado propio del arquetipo de una sociedad. Ocultaron la memoria.

Doblando hacia el norte se avistan las grandes calas y las playas de insólita belleza como Cónsul -todavía preservada- o San José -hoy en lenta degradación, que engendran, combinadas, la especulación bastarda y las políticas municipales de subrepticio consentimiento.

La maravilla ante el espacio de Cabo de Gata como lugar de comunión con la naturaleza, segundo de los motivos señalados, es una constante presente en los textos de ambos creadores, quienes traducen a sus respectivos campos la admiración por el espacio que contemplan. Esta naturaleza descrita casi como un paraíso terrenal adquiere enseguida connotaciones míticas unidas al momento de la creación, asimilando el paisaje al lugar del origen y por tanto de recuperación de la esencia del ser (Falces, 1998: 19, Valente, 2003: 57, y Valente/Falces, 1992: 3):

Territorios extraños, versátiles en escenarios de lo ficticio bajo las formas infinitamente poliédricas del espacio poético y sus innumerables manifestaciones. Escenarios que fueron un potencial de imágenes, que paulatinamente resucitan con trajes distintos en cada uno de nosotros. Una zona de plegarias en donde el sacerdote, el guerrero de la galaxia, se pregunta What Killed the Dinosaurs? ¿Qué acabó con los dinosaurios?).

En este triángulo cuya base podría ir de Carboneras a Torregarcía he encontrado un reino que no hubiera merecido conquistar y de ahí que por él haya sido conquistado. Uno no escoge los lugares y las tierras: es escogido por ellos.

Todavía encontramos en esta tierra un espacio real donde la naturaleza parece reconocerse a sí misma y donde el hombre puede, a su vez, reconocerse en ella. Reserva 
inapreciable de belleza, paraje que invita a la quietud del ánimo, a la contemplación o al despacioso movimiento sumergido en el que toda creación tiene su origen.

En tercer lugar, hemos señalado que la obra se estructura girando a partir del examen de dos tópicos fundamentales como son la memoria y la luz a partir de la palabra y la imagen, elementos que analizaremos detenidamente más adelante. Las pequeñas poblaciones, muchas de ellas abandonadas, sirven de escenario para la recuperación de la memoria a través del diálogo con los más ancianos, quienes narran la historia de los hombres del mar, historias de tiempos remotos en que todavía se practicaba la lucha entre el hombre y la naturaleza. La constante del mar y del viento como elementos que borran la vida que un día hubo evocan la reflexión sobre la memoria, mientras que la luz, reina sobre todo el territorio, y el color, en cambio constante según la hora del día, crean el efecto del paso del tiempo. En cualquier caso, todo acabará en la destrucción del hombre, en la nada, «Who killed the dinosaurs?», nadie responde entre las ruinas atravesadas por el aire.

Por último, habría que señalar una lectura real, más allá de la imagen poética y más relacionada con los dos primeros motivos aludidos. La obra se estructura como una sucesión de imágenes que bien podríamos identificar con el recorrido realizado por ambos autores y descrito en la introducción que sirve de prólogo al libro. A este respecto, hay que hacer notar el hecho de que la primera instantánea, la que abre la obra, nos muestra un camino que se dirige hacia la luz, como una invitación a emprender un viaje guiado por los autores. Igualmente, tiene especial importancia la imagen que la cierra, una mano, seguramente la del poeta, que parece despedirse del paisaje con el gesto de tomar una nube y agitarla como si de un pañuelo se tratase.

\section{La memoria}

La fotografía ha sido calificada como arte fragmentario, lo que la relaciona en gran parte con la concepción de la memoria que encontramos en esta obra no sólo en los poemas, donde se muestra de manera verbal, sino también de un modo visual a través de la interacción entre palabra e imagen. La fragmentación en ambos casos será la representación de esa recuperación de la memoria, la cual no acude a la mente del individuo como algo unitario, sino fragmentario. Podemos incluso llegar a decir que la obra al completo funciona en base a una sucesión de fragmentos de carácter visual que se van sucediendo, quedando los poemas intercalados entre la serie de instantáneas, por lo que el lector/espectador tiene que trabajar a la vez con los dos medios reuniendo las piezas como si de un puzzle se tratara para conseguir percibir el sentido global de la obra. Armando López Castro, a propósito de la memoria en Valente, señala (López Castro,1995: 129): 
Memoria y fragmento están unidos y así recuperar el origen de lo poético es recuperar la memoria [...], cuya forma se constituye en fragmento. Tan sólo en lo fragmentario, «en el reino de lo discontinuo», será posible «restaurar la imagen de lo único», el saber del origen.

Antonio Ansón destaca sobre la relación entre fotografía y memoria (Ansón, 2000: 20): «Las imágenes, entre otras cosas, quieren ser huella y testimonio de algo que ocurrió o de aquello que sucede y dejará de estar». Esta fijación de la memoria, este retrato de lo que fue y no será nunca más, es uno de los motivos que encontramos en Cabo de gata. La memoria y la luz a través de la interacción de imagen y palabra. Valente, en una entrevista concedida en el diario El País, calificó la memoria como «un inmenso contenedor» para la sociedad actual, defendiendo frente a esta concepción la búsqueda de lo concreto, por lo que el poeta busca refugio en las artes visuales caracterizadas por la captación de un instante que queda acotado dentro de la memoria, campo en el que encontramos la fotografía. En este sentido, Manuel Falces declaraba en la presentación del libro de ensayos de Valente Elogio del calígrafo (Samaniego, 2003): «La fotografía, para Valente, fue un descubrimiento decisivo en la fijación de la memoria. La imagen fotográfica equivalía a la plasmación de la palabra. Estaba obsesionado por la memoria visual».

La importancia de la memoria como recuperación y conservación de la identidad del hombre se revela como uno de los motivos fundamentales de la obra, así como una de las motivaciones que influyeron en su creación. La recuperación de la memoria en Cabo de Gata supone para estos fines la justificación necesaria para la reivindicación del espacio natural, lugar donde todavía es posible descubrir el pasado de sus habitantes $\mathrm{y}$, por tanto, el pasado del hombre en si mismo, lo que constituye una seña de identidad. Esta es la intención que reconocemos en la descripción que se hace del relato de Antonio Hernández, propietario del hostal y presidente de la asociación de vecinos de Isleta de Arráez (Valente/Falces, 1992: 5):

Su narración responde a un ejercicio lento y provocado de restauración de la memoria colectiva. Hay, ciertamente, en esa operación de la memoria un deseo imperioso de proteger la identidad del grupo y de defender sus peculiares formas de vida, aunque sin menoscabo de la necesaria mejora de las condiciones materiales que, en muchos aspectos, han sido y siguen siendo extremadamente duras.

En cualquier caso, la memoria se relacionará con el lenguaje, único medio por el que puede ser expresada y que constituirá un modo de conservación mediante su fijación en la palabra. La utilización del lenguaje como medio de recuperación de la memoria que consigue ser reconstruída poco a poco se encuentra reflejada en la descripción del discurso anterior en el que la constitución del discurso está planteada como una manera de construcción de la identidad de las personas implicadas en los 
hechos que se narran. La importancia del lenguaje en la recuperación y fijación de la memoria se verá apoyada por el uso de la imagen como plasmación y acotación de la intencionalidad y del contenido de la palabra, funcionando ambas como un intento de fijación y reconstrucción de una memoria en muchos casos perdida y que de este modo intenta ser recuperada y plasmada finalmente para su supervivencia.

La memoria será también relacionada con el elemento sagrado, especialmente con los elementos naturales como la tierra o la luz, siendo un medio, al igual que el lenguaje, por el que la divinidad se manifiesta. Este es el caso de la recuperación de la memoria común, la cual llegará a adquirir connotaciones sagradas, más cerca de la divinidad que del hombre, elemento que permite al ser reconocerse y reconocer por tanto al dios. En términos casi místicos se nos describe la manera de hablar de la tía Angélica, la persona más anciana de Isleta de Arráez que además había ejercido como partera, por lo que las connotaciones de creación toman aún mayor relieve. Hasta ella son conducidos por el propio Antonio (Valente/Falces, 1992: 6):

La tía Angélica tiene 87 años. Cuando habla, parecería descender a ella el espíritu del lugar; su voz es firme, alta vibrante, joven. Conoce las costumbres del mar y las costumbres de los hombres de la mar. Sabe cómo se calan los distintos artes y cuáles son los tiempos y los vientos que hacen la captura mayor. Ha sido además partera. La mayoría de los hombres que todavía viven en la Isleta han sido alumbrados con la ayuda de sus manos. Cuando habla, el espíritu del lugar parece manifestarse invocado por esas mismas manos. Manos grandes, de largos dedos, manos que han ayudado a nacer y que el trabajo ha ido curtiendo, pero sin hacerles perder vida ni expresión.

Esta sacralidad conseguida a través de la instrumentalidad del ser como traductor de la palabra para los hombres será considerada como la función básica del poeta quien no debe ser dueño de la palabra, sino su medio de expresión (Schvartz, 1989):

Una condición de la creación es la negación de la propiedad sobre la palabra. Así, el creador pertenece al lenguaje, del cual se convierte en instrumento. Novalis lo definió bien cuando dijo: «No es escritor quien usa el lenguaje, sino quien permite que el lenguaje hable en él». El lenguaje planteado sólo como expresión es un medio de presión.

Tía Angélica debe ser entendida bajo esta nueva lectura como imagen de la creación, cuya base es para Valente la memoria, quedando lenguaje y memoria indisolublemente unidos, ya que, como señala Teruel (Teruel, 1995:161): «la búsqueda de la memoria, de la historia, pasa por el encuentro con el lenguaje». Bajo esta idea, la persona individual se diluye convirtiéndose en contenedor de la memoria colectiva, siendo cauce de la creación poética y medio por el que la divinidad de la tierra (notemos la repetición del concepto de «el espíritu del lugar») se comunica con el exterior. La memoria, manifestada a través de la anciana, sirve como base, como inicio, motivación y fin de la creación poética que motiva la obra. En la persona de tia Angélica descubrimos el sentido y la razón de esa creación. 
Para hacer posible esta entrada de la divinidad, la que encontramos en la anciana como representación de la creación y la que es imprescindible en el artista, es necesaria la entrada en el vacío, la disolución del individuo que da paso a la comunión con el medio y con el lenguaje, pues sólo así se conseguirá llegar al origen del mensaje y a la esencia del lenguaje (Teruel, 1993: 166):

Lugar de la anonimia, del no sujeto, de la disponibilidad absoluta, donde la oposición de contrarios dibuja la unidad, el laberinto en el que entramos con la palabra y del que sólo saldremos con la palabra misma, hasta la «luz» 0 «limo original de lo viviente». Abolido el discurso, el lenguaje ingresa en una salida de sí mismo.

Esta búsqueda del vacío y de la ausencia la encontramos reflejada no sólo a través de la palabra, sino también en las imágenes que acompañan a los textos y que los completan, consiguiendo el efecto de situarnos ante un espacio que bien podría, y debe, ser aplicado a las palabras. La descripción recibe el complemento visual del espacio descrito, complementándolo y aclarándolo, fortaleciendo la idea que se quiere transmitir. Es en este punto del vacío, en la noción de espacio, en la que podemos relacionar claramente la imagen y la palabra, pues al encuentro con el vacío es a lo que nos invitan las fotografías que conforman el libro. La imagen funciona aquí como invitación a la inmersión en la ausencia que dará lugar a la creación, por tanto, a la recuperación de la memoria a través del lenguaje.

La primera de las instantáneas nos invita a la entrada en Cabo de Gata, al recuerdo, el camino que entra y se pierde y que parece dirigirnos hacia la siguiente imagen en la que nos adentramos en la secuencia que será motivo de todo el libro: las ruinas, el desierto, la vegetación que aún pervive. El camino es seguido por la imagen de las ruinas, de lo que fue la vida, para después adentrarse en la frontera de las dunas, donde aún crece la vegetación, porque la vida es posible, antes de llegar al desierto de las antiguas minas. Las imágenes del espacio vacío quedan enmarcadas así por las imágenes de la frontera, llenas de color y de luz, señal de que todavía hay esperanza para el hombre si recuerda, si no se pierde en el olvido. El fotógrafo consigue darnos un mensaje optimista a través de la plasmación del paisaje almeriense, lleno de contrastes como el ser humano, pero todavía a tiempo de ser recuperado.

La ausencia de memoria se identificará con el olvido y, por tanto, con la muerte, con la destrucción del ser que no se reconoce a sí mismo, que se encuentra perdido en una espiral de angustia existencial que desembocará en el vacío. Para mostrar este olvido identificado con la muerte serán recurrentes los símbolos de las ruinas, de la naturaleza muerta, de la pregunta sin respuesta; elementos que encontramos en muchos de los pasajes que quedan plasmados en las fotografías (Valente, 2003: 61): 
Entre las ruinas, la vegetación delgada, delicada, traza insólitos grabados japoneses. Mientras, en torno, sin piedad, el tiempo hunde los techos, cae sobre sí mismo, se devora y con él nos devora, nos deja huérfanos de toda sucesión ni antes ni después. Pregunto a quién escribo, con quién hablo, adónde voy. ¿Lo sabes? Dime, ¿dónde estamos?

La aparición de imágenes de ruinas, de pueblos abandonados donde habita el tiempo, será constante. A esto hay que unir el uso del blanco y negro, el cual servirá para acentuar la sensación de muerte, de olvido, de tiempo pasado. Las casas que quedan situadas como en un rincón de la fotografía frente al espacio abierto del desierto acentúan el abandono, la ausencia de vida, de recuerdo. Esta idea se hace todavía más clara en la imagen del cementerio, recinto cerrado donde habita la muerte frente al espacio vacío del olvido. La muerte queda olvidada, el olvido representado con la muerte que parece olvidarse a si mismo en una muerte definitiva. Pero no siempre será así, el mensaje de que todavía es posible la vida se transmite con la profusión de colores que encontramos en una de las fotografías que abren el libro y que marcan el inicio de este motivo donde el pueblo queda centrado llenando el espacio. El mismo sentido de esperanza parecen tener las imágenes en las que aparecen restos de vida: un gallo que canta en lo alto de un tejado, un niño que pasa cruzando el espacio vacío, una bicicleta en el centro de una calle, unos niños que juegan. El optimismo siempre presente, la llamada a la recuperación de la memoria reflejada en la recuperación del espacio natural, en la conservación de lo que aún queda, la reivindicación de la ayuda gubernamental para la gente que aún habita estos territorios sumidos en la pobreza. Aún es posible recordar, aún es posible la vida.

El avance constante del tiempo dará pie a la reflexión sobre la destrucción que irremediablemente acabará con la muerte dada por el olvido, elemento que encontramos una vez más en ambas disciplinas y que queda acentuado al funcionar en una clara interacción. La serie de imágenes dedicada al poblado abandonado y tomadas siempre desde la misma perspectiva a distintas horas del día responde a este reflejo del paso del tiempo. El efecto es conseguido construyendo la serie como una secuencia en la que el lector ve una sucesión de iluminaciones sobre el mismo escenario hasta completar un día entero. El tiempo pasa mientras las ruinas permanecen evocando reflexiones sobre la soledad del hombre, la destrucción y el olvido.

La desaparición de la civilización, la extinción del ser en estos territorios poblados sólo por la luz y el polvo será uno de los motivos utilizados por Valente en su producción. Algunos de los poemas insertos en la obra servirán para incitar a la interpretación de las imágenes bajo esta premisa, favoreciendo una vez más la lectura poética de las fotografías. Igualmente, en otros textos del poeta referidos a la región de Cabo de Gata encontramos elementos que remiten a estos mismos paisajes y, por tanto, a estas imágenes. Así lo describe en el ensayo «Así en la tierra como en el cielo», donde 
el sol es lo único que permanece inalterable cayendo sobre las ruinas de lo que un día fueron casas construidas por la mano del hombre (Valente, 2003: 61):

Al final está el hombre. Está, estuvo. Desusada presencia. La sucesión del tiempo. El hombre es testigo que se extingue, mas no el fuego con él. El fuego, el suyo, dura, el que un día remoto el mediador robó por él a un dios. [...] Tan sólo para alejar la muerte jamás tendrá un conjuro. Apenas puede pasar el hálito de un corazón a otro corazón; dios un momento alzado y luego sumergido para siempre en la noche.

El hombre identificado como dios caído tras la pérdida de la luz, imagen que debemos entender como el descenso de la memoria, es el tema predominante en este pasaje, donde la noche se asimila una vez más con el olvido, con la muerte a la que el hombre es condenado al perder su capacidad de recordar lo que fue, al ser imposible recuperar la luz que Prometeo robó a los dioses, hecho por el que fue castigado a la oscuridad. La incapacidad del hombre para comunicarse con la divinidad, conseguida a través de la creación y del recuerdo, como veíamos en el caso de tia Angélica, le hace quedar sumido en la noche, en el olvido y, por tanto, en la muerte. Pero sólo muere el hombre que no es capaz de ver la luz, porque la luz no se extingue, como la divinidad, sólo que al olvidarla el hombre deja de existir y sólo recordándola volverá a la vida, de ahí la necesidad de la fijación de la memoria para su conservación, que es, al fin y al cabo, la conservación de la esencia del ser.

En la obra de Manuel Falces encontramos que la luz está indisolublemente unida a la memoria como elemento utilizado para traer al recuerdo escenarios de tiempos pasados. Ella será la encargada de poblar el espacio vacío que queda lleno de luz y que inicia el proceso del recuerdo como antes vimos en la descripción de la tía Angélica en el caso de la tierra. La luz será el medio por el que la divinidad desciende a la tierra, en el vacío, invitando a la creación, indisolublemente unida a la memoria. La luz será el motivo principal de estas fotografías que reflejan la presencia constante del sol, el mismo sol que alumbra a Almería desde siempre, que consigue un tiempo en constante retroceso en la imaginación del espectador, la recuperación continua de los espacios que vuelven a ser evocados en la memoria alumbrados bajo la misma luz, aunque en el momento de la visualización sean completamente distintos a lo que fueron (Falces, 1998: 10-19):

Allí se agolparon viejas imágenes, y las palabras resucitaban espontáneamente cada vez que se las miraba y se las leía. La fotografía y la palabra rompieron el encantamiento de la vocación documental de la instantánea. Se adentraban ambas en el reino de los bosques poéticos y destrozaron todos los cristales que creyeron que una foto era un certificado de la memoria por los siglos de los siglos. [...] Junto a alguna de esas instantáneas escribí que venía de una tierra donde la memoria se confunde con la luz. Ahora estoy en otra -Lanzarote- que comparte esta parte del alma y su paisaje de forma gemela con la mía. Donde la piedra es fácilmente traducible a la vez en silencio y en verbo, porque es la imagen y la luz, la memoria y lo desconcertante de un instante en blanco. [...] Escenarios 
que fueron un potencial de imágenes, que paulatinamente resucitan con trajes distintos en cada uno de nosotros.

La destrucción del ser se igualará con la muerte real representada por la imagen del cementerio, pero también con el olvido, entendido como la muerte definitiva, justificación de ese afán por la recuperación de la memoria que aparece como uno de los motivos recurrentes en la obra como una forma de evitar la muerte completa. En cierto modo, la fotografía será vehículo para esta fijación de la memoria visual, como prueba de la veracidad de que un día existió realmente la vida.

El motivo de la pesca, de la vida unida al mar del que se habla en la introducción, servirá como símbolo para la representación del olvido y del recuerdo, de la muerte y de la vida. El mar unido a la muerte, la tierra unida a la vida. La constante aparición de la imagen de la playa, en muchos casos tomada en blanco y negro, nos recuerda la necesidad de la muerte para que exista la vida, la necesidad del olvido para que exista el recuerdo. La imagen de las olas que bañan la playa tendrá como culminación la imagen de las barcas varadas en tierra que acompaña a las palabras de Valente (Valente/Falces, 1992: 47): «Tenía el mar fragmentos laminares de noche. Los arrojaba al día. Para que el ave tendida de la tarde no pudiera olvidar su origen en los terribles poros anegados del fondo». Una vez más se nos llama la atención sobre la necesidad del espacio vacío para poder recordar, de ahí que el mar arroje «fragmentos laminares de noche» al día, alertando sobre la posibilidad de olvidar, sobre la necesidad de traducir los recuerdos, la memoria común, al lenguaje de los hombres, para que así no se pueda olvidar el origen y sea posible la continuación de la vida. El optimismo una vez más tiene su aparición en estas palabras en las que todavía es posible recordar, en el vacío arrojado de la noche el ave puede recordar. Y es esta misma idea a la que nos remite el uso del color y en especial, la imagen del arcoiris que parece surgir del mar, imagen de la muerte y del olvido. Si el hombre es capaz de recordar todavía habrá una esperanza para la vida. Esta será la misión del artista.

La meditación ante las ruinas da pie a la pregunta sobre la existencia, a la súplica por saber de las gentes que poblaron aquellos lugares en una suerte de devolverlos a la vida a través de la evocación de su recuerdo. Pero la ausencia de respuesta tendrá como consecuencia la angustia por la conciencia del olvido, llegando a dudar si realmente existió algo o es simplemente una ilusión. La imagen del camino que da entrada a un pueblo que quedó vacío, donde sólo la luz de la tarde puebla la casa que parece vislumbrarse al final del sendero que conduce a su puerta, los árboles resecos, la luz rojiza que desciende del cielo y se refleja sobre la tierra, todo parece adquirir un aura irreal, de espejismo de vida que hubo y ya no hay. Y es esa ausencia de vida la que hace dudar de la veracidad de la silueta del hogar que parece verse al fondo, llegando a 
confundirse con el terreno que se levantan alrededor y que parece asumirla como parte de él (Valente/Falces, 1992: 87):

Imágenes de imágenes de imágenes. Textos borrados, reescritos, rotos. Signos, figuras, cuerpos, recintos arrasados por las aguas. Piedras desmoronadas sobre piedras. Lugar que ahora sobrevuela el polvo. Morada sin memoria, ¿quién te tuvo? Tiempo hambriento de ser evaporado en la noche. Siembras palabras y responden ecos, ecos de ecos en la bóveda incierta de la desolación. Daría todo el aire por un grito, la posesión del reino por un solo gemido. Abrieron los augures las entrañas del dios y entregaron un cuerpo lacerado a los depredadores.

La ausencia de recuerdos, de memoria, dejan entrever una imagen que podríamos asimilar a la de una cáscara vacía, sin contenido. Lo que fueron muros sólidos quedan reducidos a ruinas: «piedras desmoronadas sobre piedras», y nada queda de lo que fue el hogar, vacío de memoria y, por tanto, de vida. La ausencia dará lugar a la reflexión sobre el paso del tiempo que arrastra la memoria hacia la muerte, identificada con la oscuridad y con la noche: «Tiempo hambriento de ser evaporado en la noche». La ausencia de vida, de esencia en el ser, dará lugar a la percepción de la realidad como un espejismo, como algo que realmente no existe porque está muerto: «Imágenes de imágenes de imágenes». Las ruinas sólo serán el intento de ser lo que fueron, la reescritura de un texto que se redime a si mismo superponiéndose al anterior, pero que siempre termina siendo olvidado para finalmente desaparecer. El hogar se presenta aquí como una hoja en la que las vidas se van registrando, superponiéndose las unas a las otras, borrándose, rompiéndose, olvidándose y muriendo al caer en el olvido. Las imágenes del viento y el eco que retumba sin respuesta contribuyen a la construcción de una imagen que acompaña a la palabra recalcando la desolación que encontramos en las fotografías reflejada y concretizada.

El encuentro con unas minas de cobre hará posible que la memoria se refleje más allá, llegando a adquirir connotaciones casi mágicas en su recuperación de lo que fue, llegando a creer descubrir las huellas de unos dinosaurios que nunca existieron, demostrando así la confusión entre recuerdo e imaginación. Este hecho rompe no sólo con la falsa recuperación de la memoria que finalmente resulta engañosa, sino que llega también a plantear la veracidad de la fotografía abriendo el camino hacia la interacción entre la lectura visual y la poética. Una vez más, la maravilla ante lo descubierto dará lugar a la meditación del poeta sobre la muerte y la destrucción del ser, de la vida (Valente/Falces, 1992: 75):

Who killed the dinosaurios?, preguntas mientras clavas en mi pupila tu pupila azul. ¿O quién? ¿Tú misma, un meteoro, una erupción volcánica? ¿Murieron uno a uno apuñalados o fueron víctimas tempranas de una súbita y calculada exterminación? 


\section{La luz}

Como ya hemos señalado anteriormente, Cabo de Gata se caracteriza por las grandes extensiones pobladas de luz, espacios vacíos donde la luminosidad reina llenándolo todo. Esta percepción de la luz es uno de los motivos principales, uno de los ejes en torno a los que gira la obra, junto a la memoria, con la que se relaciona íntimamente. Sin embargo, esta percepción variará mucho en los dos autores para los que la luz, aun teniendo connotaciones muy parecidas, causará sensaciones muy diferentes.

Para Manuel Falces, almeriense de nacimiento, esta luz forma parte del escenario en el que se ha desarrollado su vida por lo que la mezcla con la memoria será constante en su percepción de la realidad, la cual vemos reflejada en las fotografías que componen el libro y en otras muchas contenidas en su obra Contrapunto mediterráneo. En todos los casos, la luz juega un papel principal en la obra de este artista que ha convivido con la luminosidad del sur y para el que la luz es un elemento esencial para la vida y un detonante constante del recuerdo. La sucesión de imágenes de lugares bajo distinta luz responderá en gran parte a la intención de mostrar el paso del tiempo, el transcurso de la vida marcado siempre por la luz solar.

Por el contrario, para Valente toda esa luminosidad resulta algo nuevo y desconocido, algo nunca visto antes mas que en la imaginación. El tema de la luz como elemento asimilado al conocimiento y al descubrimiento de la verdad es una constante a lo largo de toda la producción del poeta gallego, pero nunca será tan cierta como en el momento en el que la luz se hace realidad y se plasma sobre la naturaleza. La palabra puede entonces descubrirse como una realidad que se realiza en este lugar (Valente, 2003: 57): «Venía de otros parajes más oscuros y hallé aquí la gravitación solar de la luz. La luz, la transparencia. Su leve peso que incendia la mirada y nítidos dibuja los precisos perfiles de la sierra hasta llegar al mar».

El Cabo de Gata es presentado por ambos creadores como un lugar donde la luz habita y existe de manera real, bañándolo todo con su luminosidad, más o menos intensa según la hora del día, lo que dará pie a la interpretación de esa luz bajo distintos motivos, en muchos casos relacionados con la presencia de la divinidad.

El juego entre la luz y la sombra plasmado por el fotógrafo en cada una de las fotografías con el uso de toda una serie de matices de tonalidades que van desde el blanco y negro hasta la profusión de colores servirá como base de experimentación para demostrar las posibilidades creadoras y reveladoras de la luz. La sucesión de las distintas horas de luz hasta la aparición de la noche y el amanecer contribuirán para la ilustración de algunos de los tópicos del poeta como la dicotomía luz/sombra. La plasmación de los mismos escenarios bajo el uso de las distintas técnicas del blanco y 
negro o el color, como en el caso de las fotografías dedicadas al desierto donde crece la vegetación, funcionarán como llamada de atención sobre las posibilidades de la luz en este territorio y, una vez más, como una llamada a la esperanza, a la existencia de la vida en el terreno más inhóspito, a la posibilidad de recordar y de redimirse. Todo es extremo en esta tierra donde la luz reina en alternancia con la sombra, donde el calor intenso convive con el frío más helador, donde el silencio asciende hacia el cielo «como un gran alarido», donde la memoria lucha por sobrevivir frente al olvido. Juego de contradicciones que se refleja también en las fotografías en los constantes cambios de tonalidad, reflejando el suelo quebradizo por la sequía y la inmensidad del mar. El uso del blanco y negro en gran parte de las instantáneas potenciará la presencia de la luz que parece provenir del fondo, de la línea del horizonte y que se refleja en el cielo, con la intensidad de las nubes, y en la tierra, creando contraluces con las siluetas de los árboles que quedan situados en medio de la distancia.

La luz que lo devora todo, que todo lo baña, que todo lo ilumina será marca de la desolación, pues sólo ella habitará muchos de los rincones aumentando la sensación de soledad, de muerte. El calor, el óxido, el oro envuelto en sangre, serán algunas de las imágenes utilizadas por el poeta para referirse al espacio no habitado que quedará sumido con la caída de la tarde en la sombra, en la muerte definitiva que provienen de la misma luz, porque, como hemos visto antes, no hay luz sin sombra ni sombra sin luz. El silencio, el vacío, la excesiva claridad en el caso de la imagen, la luz reflejada sobre las plantas doradas o el color rojizo que adquiere la imagen serán los motivos que representen la muerte (Valente/Falces, 1992: 105):

\footnotetext{
El oro envuelto en sangre de las tierras del sur. Los perros vagabundos llegaban hasta el límite frío de los vientos para morir. Nadie habitaba ya el lugar incierto. Óxidos. Nadie. Los luminosos cuarzos amarillos incendiaba en su rápido descenso el sol. Después la sombra como una antorcha helada en todos los caminos que llevan al vacío. La soledad hambrienta devora las figuras. Sube el silencio contra el cielo, enorme, como un gran alarido.
}

La luz será identificada en algunas ocasiones con la fuerza totalizadora representada por el poder, así también la noche, que traerá la muerte tomará en algunos casos esta significación. Peinado Elliot ha señalado (Peinado Elliot, 2002: 37): «la totalidad que amenaza al individuo se presente a José Ángel Valente bajo la forma política de la opresión de un sistema dictatorial que controla y abarca toda la realidad». La plenitud solar se contrapone a la tierra sobre la que cae, dejándola reseca y agrietada; sólo en la sombra es posible refugiarse y hacia allá huyen los animales buscando poder sobrevivir. La autoridad queda identificada con esta luz que cae sin piedad y a la que es imposible dirigirse por miedo a ser aniquilado. No hay lugar para la oposición (Valente/Falces, 1992: 59): «La paciencia del sur. Sus enormes lagartos extendidos. El 
caparazón oscuro de la noche mordido por la sal. No llega la pregunta a convertirse en signo. Interrogar, ¿por qué? ¿Quién nos responderá desde la plenitud solar sin destruirnos?».

Este espacio donde habita la luz es identificado con el altar donde rendir culto a la divinidad creadora, lugar donde el sacerdote, a través de la palabra, es capaz de reflexionar sobre la existencia: «ipor qué?». Este es el motivo que descubrimos en una de las instantáneas donde una pequeña capilla recibe la caída de la luz solar. Tres planos se distinguen en esta instantánea donde la tierra y el mar quedan en penumbra en la franja inferior, el cielo refleja el resplandor que destaca en el medio plano la capilla que se recorta en el horizonte y, desde lo alto del cielo, completamente centrada y en línea directa sobre la iglesia, queda situada la caída de la luz solar.

En el proceso de conocimiento de la divinidad el hombre se caracteriza por su incapacidad para percibir la esencia de lo sagrado por sus propios medios, por lo que es el elemento sagrado el que tiene que hacerse presente ante los sentidos del ser que lo reconoce. Es este paso, que posibilita la percepción a través de los sentidos, el que podemos descubrir en las imágenes que ilustran la obra, en las que la luz emana de algún lugar en el fondo de la instantánea, consiguiendo que la luminosidad traspase el papel y se presente ante nosotros partiendo de las propias páginas del libro. Tomemos por ejemplo la imagen del cielo, el cual ocupa la mayor parte del espacio, donde las nubes parecen hacerse reales sólo en el momento en el que el sol incide sobre ellas. Todo el cielo parece estructurarse en torno a ese punto de luz del que todo parece emanar, donde todo tiene su origen.

Una vez percibida la presencia de lo sagrado, los objetos iluminados por esa luz pueden ser percibidos en su forma verdadera, reflejo de la verdad divina. La luz emana del interior de los elementos mismos al igual que la sombra, pues una y otra quedan indisolublemente unidas. Los objetos así iluminados se nos presentan como bellos y, por tanto, verdaderos, siguiendo el ideal platónico de la belleza unida al concepto de verdad. Sólo a través de la iluminación podremos llegar al verdadero conocimiento, por lo que la luz funcionará también como representación de esta revelación. De ahí el valor de la luz como elemento que nos permite conocer realmente, como herramienta de la verdad y como muestra de la creación en todo su esplendor (Valente 2003: 55): «La luz, la cal, el color, el mar. El color no es adjetivo; es señal sustantiva de la diversidad del mundo».

La horizontalidad constituida por la imagen del sol en lo alto del cielo y cuya luz se extiende en todas direcciones, será a veces símbolo de la elevación del espíritu gracias a la observación y a la comunión con el medio, apareciendo el vuelo del pájaro como representación de este elemento (Valente, 2003: 58): «Todo aquí se levanta, se 
382 Tropelías. Revista de Teoría de la Literatura y Literatura Comparada, 19 (2013)

Concepción Torres Begines

alza y nos levanta, como al pájaro solitario que vuela sin amigo en los más altos territorios».

La luz será también identificada con la figura del dios creador, soberano de todo lo que puebla la tierra y que baña todos los elementos con su luminosidad, repartiéndose entre todos los objetos de su creación. La inmensidad de la divinidad se encuentra representada por la extensión de la luz solar, pero también con la extensión del mar en el que se refleja y que, al igual que la luz en este territorio, parece no tener fin. La profundidad del mar será también a veces identificada con la sombra, con el olvido y con la muerte, funcionando entonces la luz como sinónimo del recuerdo y, por tanto, de la vida (Valente/Falces, 1992: 25): «No sabríamos decir cuánto debemos ya a esta luz, que puede ser alta y terrible como un dios o declinar como animal de fuego hacia el crepúsculo, arrastrando con ella todo el cielo hacia la línea donde no acaba ciertamente el mar».

\section{Bibliografía}

ANSÓN, Antonio (2000): Novelas como álbumes. Fotografía y literatura. Madrid, Mestizo.

DAYDÍ-TOLSTON, Santiago (1994): «Contrastes de luz y sombra como técnica de representación en la poesía de José Ángel Valente», en Claudio RODRÍGUEZ FER, Material Valente. Gijón, Júcar.

FALCES, Manuel (1993): «El manuscrito de D. Lyon», El País, Cultura (15/03/1993).

- (1998): Temperamentos fotográficos. Lanzarote, Fundación César Manrique.

— (2000): «Compartir la mirada», El País, Cultura (19/07/2000).

(2001): «Imágenes de imágenes», El País, Babelia (15/12/2001).

HUGHES, Alex, y NOBLE, Andrea (2003): Phototextualities: intersections of photography and narrative. Albuquerque, University of New Mexico.

LÓPEZ CASTRO, Armando (1995): «José Ángel Valente: Memoria del verbo», Cuadernos para la Investigación de la Literatura Hispánica, 20, pp. 132-152.

PEINADO ELLIOT, Carlos (2002): Unidad y trascendencia. Estudio sobre la obra de José Ángel Valente. Sevilla, Alfar.

SAMANIEGO, Fernando (2003): «José Ángel Valente unió poesía y pintura en sus ensayos sobre arte», El País (29/01/2003).

SCHVARTZ, Carlos (1989): «José Ángel Valente "al dios del lugar"», El País, (12/04/1989).

TERUEL BENAVENTE, José (1993): «En la extensión vacía de la memoria: un itinerario por la poesía de José Ángel Valente», Revista Hispánica Moderna, 46/1, pp. 157-178. 
Tropelías. Revista de Teoría de la Literatura y Literatura Comparada, 19 (2013) 383 Miradas compartidas: Valente y Falces

VALENTE, José Ángel (2003): Elogio del calígrafo. Barcelona, Galaxia Gutemberg.

VALENTE, José Ángel, y FALCES, Manuel (1992): Cabo de Gata. La memoria y la luz. Granada, Unicaja. 